\title{
Fuzzy control strategy of DC torque motor with DSP Builder
}

\author{
Yan Zhang $^{1}$, Xiaoyu Zhang ${ }^{2}$ \\ ${ }^{1}$ Changchun Institute of Optics, Fine Mechanics and Physics, Chinese Academy of Sciences, \\ Changchun 130033, China \\ ${ }^{2}$ Changchun Institute of Optics, Fine Mechanics and Physics, Chinese Academy of Sciences, \\ Changchun 130033, China
}

15500027661@163.com

Keywords: DSP Builder, DC torque motor, Fuzzy control, PID, Speed control.

\begin{abstract}
Due to the non-linearity, randomness factors in the process of actual control, we always can't get the accurate mathematical model of controlled object and the disturbances from outside may also cause serious influence to the controlled system, in this case using the conventional PID controller often cannot get satisfactory control effect. To make up for the shortage of the conventional PID controller, and overcome the outside factors, ensure the normal operation of the system. This paper presents a fuzzy theory combine with PID control technology and gets a new control method, then analyses the characteristics of fuzzy control and conventional PID control, and build a closed loop control system model with DSP Builder, make simulation analysis and actual speed control experiment. Experimental results show that, compared with the conventional PID controller, fuzzy PID controller's major dynamic parameters are better, when targets' parameter and structure getting a great change, the system's ability to maintain the stability of motor speed control system is greatly enhanced. Compared with the conventional PID control, the proposed control algorithm in the aspect of dynamic characteristics and stability has a clear advantage.
\end{abstract}

\section{The introduction}

The DC torque motor has the advantages of simple control, long time working in the condition of blocking, fast response and high precision. It is widely used in high precision position and speed control system of rotary table, radar, and inertial navigation system ${ }^{[1]}$. At present, the main control method is Proportion, Integration, Differentiation control, referred to as PID control, the algorithm is simple, robust and reliable, but the real time delay and nonlinear coupling of the system can cause the uncertainty of the controlled object. The traditional PID can not make the ideal motor control effect. To solve this problem, the researchers used such as Lead lag control algorithm ${ }^{[2]}$, Modular theory ${ }^{[3]}$ and PID control algorithm based on iterative learning ${ }^{[4]}$ to control the motors. But there are some problems, such as the need to know the mathematical model of the controlled object, the practical application is difficult to achieve, not easy to operate, and the calculation is more complex and so on. In order to make up for the shortcoming, this paper puts forward the fuzzy PID control method, according to the experience of debugging personnel to design a fuzzy controller. It can overcome the shortcomings of traditional PID controller in strong interference or load, bad ability to adjust the changing parameters and exert the advantages of simple, high reliability and easy to implement. It can quickly achieve the control effect which is difficult to achieve with the classical control theory. It can make a superior performance when is difficult to establish a precise mathematical model of the nonlinear control process demonstrated ${ }^{[5-6]}$.

Signal Processing Digital (DSP) is widely used in the field of control. This system is relatively cheap and easy to use. However, in DSP, it is necessary to implement the control algorithm in software programming, and then implement it through compiling and downloading which leads to the poor flexibility in modeling and control of the control object.

With the development of Programmable Gate Array Field (FPGA) technology, its integration leve is more and more high, an embedded microprocessor and DSP and so on. Greatly improve the flexibility of the system. This paper presents a design scheme of the experimental system based on the 
FPGA platform. Combined with Builder DSP Technology, the simulink model file can be directly converted into a controller used by the code file. connect with the hardware, has the advantages of rich software and hardware resources, and the simulation and control algorithm is flexible, the volume is small, the cost is low, and the use is convenient.

\section{Fuzzy control algorithms research}

\subsection{The uncertainty of dc torque motor model}

Dc torque motor is applied in high precision servo system, the friction torque is an important factor affect the system performance, because of the friction torque has the characteristics of nonlinearity, uncertainty, hysteresis, it caused great difficulties to obtain the mathematical model of controlled object. In addition, the motor torque's fluctuation and model parameters time-varying characteristics, load fluctuation, and many other factors lead it difficult to establish accurate model in the simulation. So in order to obtain good control effect we should improve the control algorithm ${ }^{[7]}$.

\subsection{Fuzzy control algorithm}

PID control rule is:

$$
u(\mathrm{t})=\mathrm{K}_{\mathrm{p}} \mathrm{e}(\mathrm{t})+\mathrm{K}_{\mathrm{i}} \int e(\mathrm{t}) \mathrm{dt}+\mathrm{K}_{\mathrm{d}} \frac{d e}{d t}
$$

$\mathrm{e}(\mathrm{t})$ is a system of deviation between the output and input, $K_{p}, K_{i}, K_{d}$ are proportion, integral, differential respectively.

With the development of control technology, the shortcoming of traditional PID control gradually emerge: it is difficult to obtain satisfactory control effect in nonlinear system; Can't change controller parameters according to actual condition, adaptability to parameter change is not strong; Need to know the control object's mathematical expression, it is difficult to implement in practical application.

Fuzzy control is on the basis of the classical control method using fuzzy set theory, fuzzy language variables and fuzzy logic reasoning to simulate human thinking method to control the system, So when the controlled object changes, the fuzzy controller can reference set of fuzzy control rules, correctting the controller parameter automatically, which greatly improves the system robustness ${ }^{[8-10]}$.

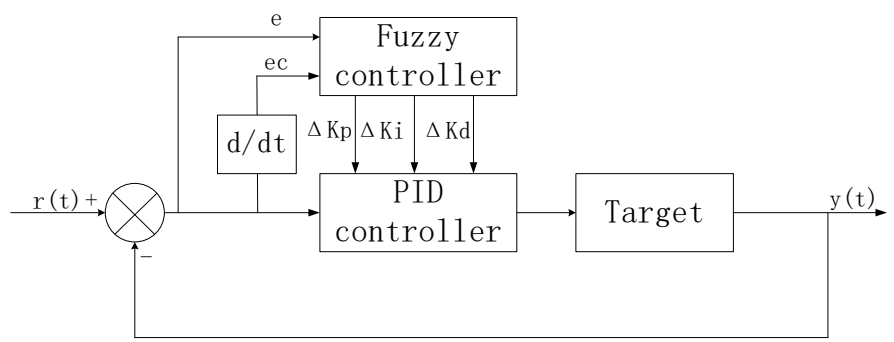

Fig 1. Fuzzy PID controller structure

The fuzzy PID controller structure is shown in figure 1, put the input deviation change rate ec as the two-dimensional fuzzy controller's inputs, put the $K_{p}, K_{i}, K_{d}$ 's variation $\Delta K_{p}, \Delta K_{i}, \Delta K_{d}$ as the controller's outputs, using the fuzzy control rules setting the PID parameter online. Fuzzy control part includes obscure calculation of settlement fuzzification, fuzzy reasoning ${ }^{[11-12]}$.

\subsubsection{The determination of input and output variables}

To reduce the amount of calculation, this article adopts incremental PID control algorithm, put the change of the three parameters of PID controller as the input. Adjust the $\mathrm{K}_{\mathrm{p}} 、 K_{i} 、 K_{d}$ 's calculations formula into:

$$
\left\{\begin{array}{c}
K_{p}=K_{p}^{\prime}+\left\{e, e_{c}\right\} K_{p}=K_{p}^{\prime}+\Delta K_{p} \\
K_{i}=K_{i}^{\prime}+\left\{e, e_{c}\right\} K_{i}=K_{p}^{\prime}+\Delta K_{i} \\
K_{d}=K_{d}^{\prime}+\left\{e, e_{c}\right\} K_{d}=K_{d}^{\prime}+\Delta K_{d}
\end{array}\right.
$$


$\mathrm{K}_{\mathrm{p}}, \mathrm{K}^{\prime}{ }_{\mathrm{i}} 、 \mathrm{~K}_{\mathrm{d}}$ are the initial parameters of proportion, integral and differential, this paper uses the Ziegler Nichols method to get them.

\subsubsection{The Selection of variable domain and membership functions}

Set e 、 $\mathrm{e}_{\mathrm{c}}$ 's domain as [-3,3], $\Delta \mathrm{K}_{\mathrm{p}} 、 \Delta \mathrm{K}_{\mathrm{i}} 、 \Delta \mathrm{K}_{\mathrm{d}}$ 's variable and basic domain as [-3,3], quantitative level is $\{-3,-2,-1,0,1,2,3\}$, Divided fuzzy subset of variables into NB, NM, NS, $\mathrm{ZO}$, PS, PM, PB\}, when choose a membership function, triangle function sensitivity is high, evenly distributed it in the center of the theory of variable domain, through testing choose $\mathrm{Z}$ function in NB, choose $S$ function in $\mathrm{PB}$.

\subsubsection{Fuzzy reasoning arithmetic and clarification}

Fuzzy reasoning is the theory basis of fuzzy control rules form. Using Mamdani method, clarification method is center of gravity method.

\section{Fuzzy PID control algorithm simulation}

When using DSP builder to simulation the fuzzy controller, use the look-up table method, First of all, establish fuzzy rule table in the case of offline, put the fuzzy control table into memory, then according the result to get the $\Delta \mathrm{K}_{\mathrm{p}} 、 \Delta \mathrm{K}_{\mathrm{i}} 、 \Delta \mathrm{K}_{\mathrm{d}}$ 's accurate value. At last, on the basic of PID conroller's initial value to adjust the values, fuzzy controller parameters is shown in table $1,2,3$.

Table 1. $\Delta K_{p}$ fuzzy control rule table

\begin{tabular}{llllllll}
\hline $\mathrm{e}$ & -3 & -2 & -1 & 0 & 1 & 2 & 3 \\
\hline-3 & 3 & 2.75 & 2.25 & 1.75 & 1 & 0.25 & 0 \\
\hline-2 & 2.75 & 2.08 & 1.67 & 1.08 & 0.5 & 0.08 & -1.5 \\
\hline-1 & 2.25 & 1.75 & 1.33 & 0.67 & -0.08 & -0.67 & -1.25 \\
\hline 0 & 1.75 & 1.25 & 0.75 & 0.08 & -0.67 & -1.17 & -1.75 \\
\hline 1 & 1.25 & 0.67 & 0 & -0.67 & -1.17 & -1.58 & -2.25 \\
\hline 2 & 0.75 & 0 & -0.67 & -1.25 & -1.58 & -1.83 & -2.75 \\
\hline 3 & 0 & -0.5 & -1.5 & -2 & -2.25 & -2.75 & -3 \\
\hline
\end{tabular}

The key of FPGA design is the design of the controller based on DSP Builder, DSP Builder is a signal processing development tools developed by Altera corporation that based on Simulink environment, support the FPGA's development process throughout, support graphical modeling and simulation, use the Signal Compiler converts graphical model into HDL files, which can be called directly in Quartus II.

Table2. $\Delta K_{i}$ fuzzy control rule table

\begin{tabular}{llllllll}
\hline $\mathrm{e}$ & -3 & -2 & -1 & 0 & 1 & 2 & 3 \\
\hline-3 & -3 & -2.75 & -2.25 & -1.75 & -1 & -0.25 & 0 \\
\hline-2 & -2.75 & -2 & -1.58 & -1 & -0.5 & 0 & 0.5 \\
\hline-1 & -2.25 & -1.67 & -1.17 & -0.58 & 0.08 & 0.58 & 1 \\
\hline 0 & -2 & -1.25 & -0.67 & 0 & 0.67 & 1.25 & 2.5 \\
\hline 1 & -1.5 & -0.67 & -0.08 & 0.58 & 1.17 & 1.75 & 2.75 \\
\hline 2 & -0.5 & -0.08 & 0.5 & 1 & 1.58 & 2.08 & 3 \\
\hline 3 & 0 & 0.75 & 1 & 1.75 & 2.25 & 2.75 & 3 \\
\hline
\end{tabular}

Table 3. $\Delta K_{d}$ fuzzy control rule table

\begin{tabular}{|c|c|c|c|c|c|c|c|}
\hline $\begin{array}{l}\mathrm{e} \\
\mathrm{e}_{\mathrm{c}}\end{array}$ & -3 & -2 & -1 & 0 & 1 & 2 & 3 \\
\hline-3 & 1 & -1 & -2.5 & -3 & -2.75 & -1.5 & 1 \\
\hline-2 & 0.75 & -1 & -1.75 & -1.92 & -1.58 & -0.83 & 0.5 \\
\hline-1 & 0.5 & -0.75 & -1.33 & -1.42 & -1.08 & -0.67 & 0 \\
\hline 0 & 0 & -0.5 & -0.75 & -0.75 & -0.67 & -0.42 & 0 \\
\hline 1 & 0.75 & 0.08 & -0.17 & 0 & 0 & 0.25 & 1.5 \\
\hline 2 & 2.25 & 0.75 & 0.67 & 0.75 & 0.67 & 0.92 & 2.25 \\
\hline 3 & 3 & 2.25 & 2 & 1.75 & 1.25 & 1.5 & 3 \\
\hline
\end{tabular}




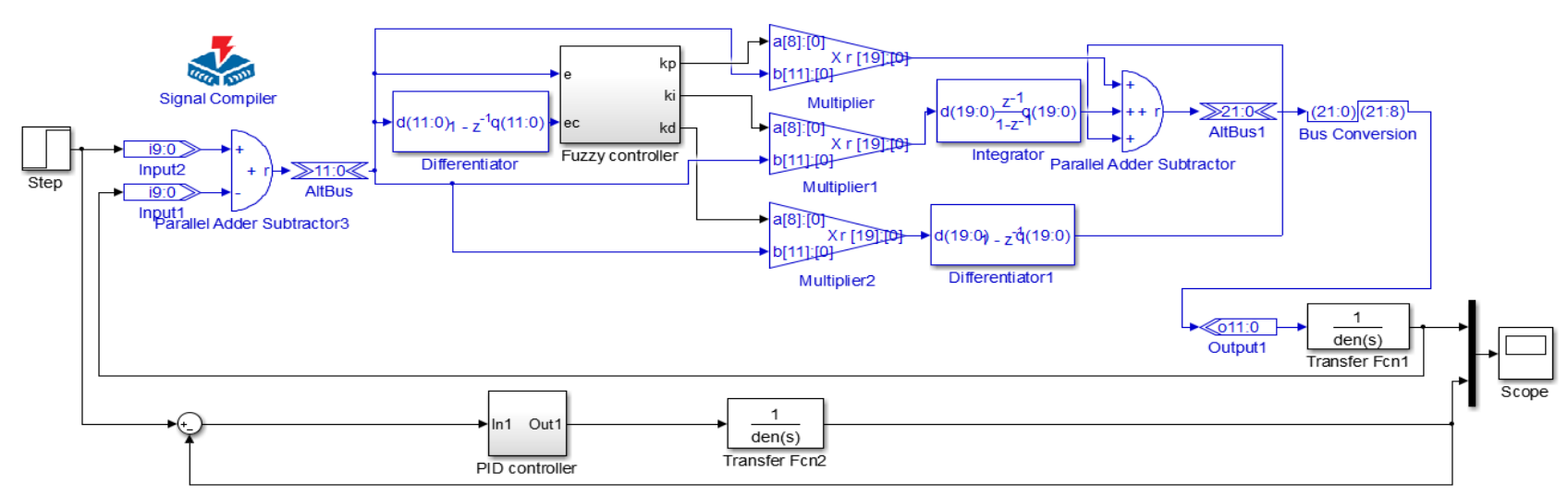

Fig 2. System simulation diagram

The Fuzzy controller in fig2 is the look-up table fuzzy controller, after completing the model, store the fuzzy control table in ROM, call it directly among runtime, it can easily validation and improvement the algorithm from the hardware level.

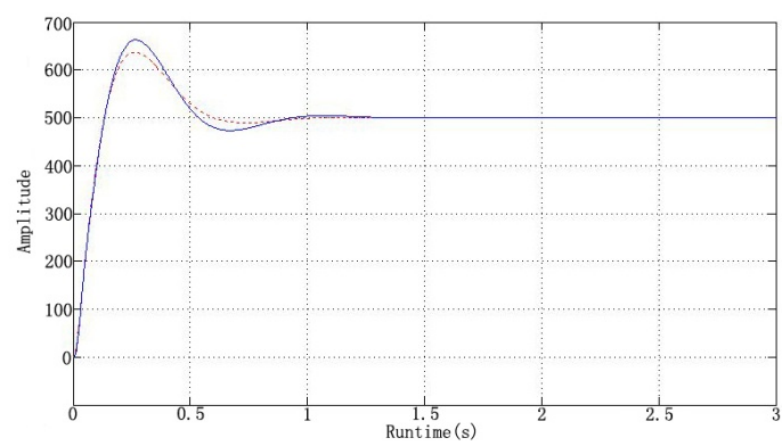

Fig 3. step response curve

System simulation curve as shown in figure 3, the implementing line is the response curve of the PID controller, the dotted line is the response curve of the fuzzy controller, the simulation time is 4s. The two curves of dynamic characteristic parameters as shown in table 4:

Table 4. dynamic characteristic parameters

\begin{tabular}{ccc}
\hline control mode & PID & Fuzzy PID \\
\hline Overshoot & $18 \%$ & $14 \%$ \\
\hline Adjust the time(s) & 1.3 & 1.1 \\
\hline Rise time(s) & 0.17 & 0.16 \\
\hline
\end{tabular}

By the table available, the overshoot, adjustment time, rise time and other dynamic characteristics of indicators the motor speed control system using fuzzy PID controller are better than that using PID controller, the advantage of fuzzy controller is obvious.

Compared with the traditional PID controller, the most important advantages of the fuzzy controller is when the parameters of the controlled object or structure occurs great changes due to various interference, it still can guarantee the stability of the system.

To verify the performance of the fuzzy controller is designed in this paper, according to the existing dc torque motor of motor parameters, controlled object expression are $1 /\left(0.012 s^{2}+1.21 s+1\right), 1 /\left(0.2 s^{2}+3.21 s+3\right), 1 /(4 s+2)$. On the premise of not changing other parameters controller structure, the system response curve is shown in figure 5 .

In figure 4 red solid line for the corresponding control object is $1 /\left(0.012 \mathrm{~s}^{2}+1.21 \mathrm{~s}+1\right)$, the blue long dotted lines is $1 /\left(0.2 s^{2}+3.21 s+3\right)$, green short dotted line is $1 /(4 s+2)$. When the controlled object changes, system response curve is not obvious change. Thus it is concluded that: fuzzy controller is not only adaptable to controlled object parameters change, and in the case of object 
model in great changes of the structure, can achieve good control effect, disturbance rejection performance is better.

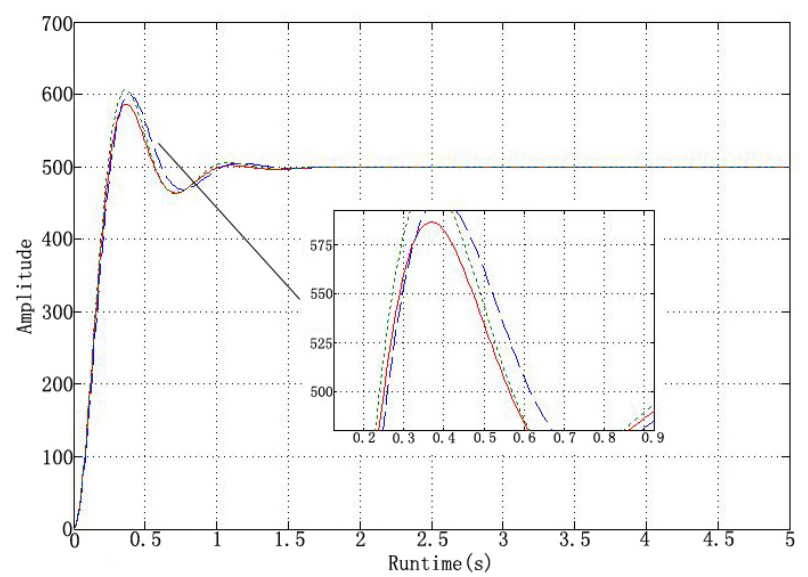

Fig 4. variable fuzzy PID controlled object response curve

By the simulation results it can be seen that under the same input signal, for the same object, the system dynamic characteristics of fuzzy PID controller has a distinct improvement. When great changes taken place to the controlled object, the system's response curve of fuzzy PID controller not get a great change, the stability is good. Proved that compared with the traditional PID controller the fuzzy PID controller designed in this paper has a great improvement in the aspect of dynamic characteristics and stability of the system, demonstrate the superiority of the fuzzy PID control algorithm.

\section{Experimental verification}

\subsection{The experimental system}

After the simulation on control algorithm, build experiment system to verify the operation of the control algorithm in practical application, this article use dc torque motor speed experiments of one-dimensional experiment of shafting as shown in figure 5, the experiment is consist of one high precision dimension of shaft system and a high precision Hydehan encoder. One dimensional precision of shafting is less than 1", the precision of the Hyde han type absolute encoder is 29.

The experimental system overall block diagram as shown in figure 6 , the driver module converts the 220v alternating voltage into dc voltage and then regulating the speed motor. The FPGA and DSP Builder module completes the movement of dc motor state data collection, transmission and control, PC used for parameter setting and data display.

Motor speed control experiment is divided into two parts: first is to validate the same dc torque motor respectively using conventional PID and fuzzy controller for speed control, observe speed regulating process and stability, compare the characteristics of two kinds of control algorithm; second is use the same fuzzy controller on three different parameters of dc torque motor for speed control experiment, contrast the system dynamic characteristics when the controlled object changed.

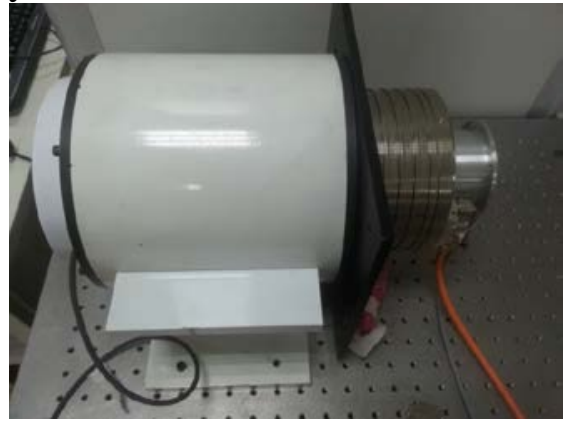

Fig 5. Experiments of shafting 


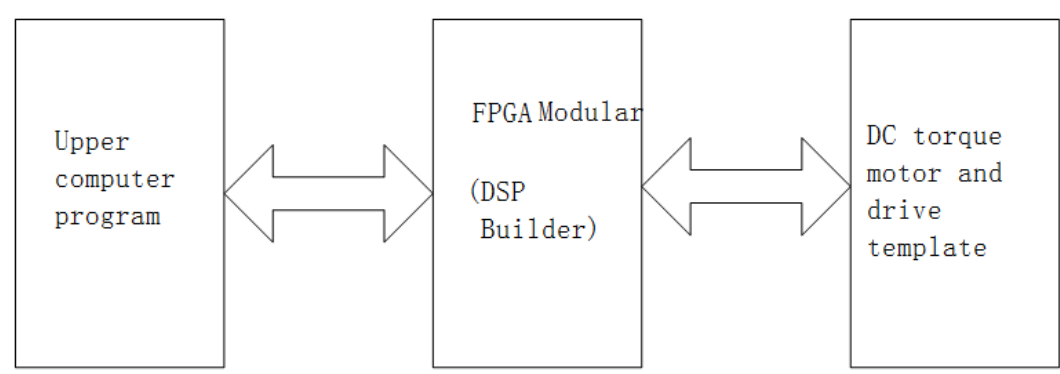

Fig 6. experimental system structure diagram

\subsection{Fuzzy PID control algorithm of speed control experiment}

Figure 7 is the speed response data graph of same dc torque motor under the conventional PID controller and fuzzy controller respectively, the target speed is $500 \mathrm{r} / \mathrm{min}$, motor speed value is measured by the encoder, the red curve is the speed curve of the fuzzy controller, blue curve is the speed curve for the conventional PID controller, the main dynamic characteristic parameters as shown in table 5, fuzzy controller of overshoot is about $22 \%$, adjust time is $1.3 \mathrm{~s}$, rise time is $0.21 \mathrm{~s}$, overshoot of PID controller is about $25 \%$, adjust time is $1.5 \mathrm{~s}$, rise time is $0.23 \mathrm{~s}$.

Experimental data show that for the same dc torque motor, the dynamic characteristics and stability of fuzzy controller that designed in this paper is better, can obtain better control effect, in accordance with the simulation results.

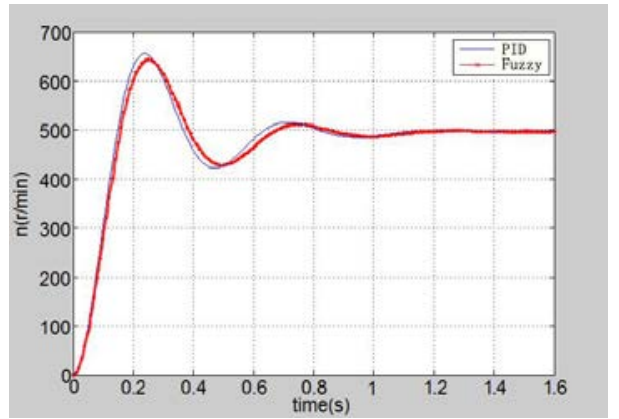

Fig 7. Variable algorithm speed data curve

Table 5. Speed dynamic characteristics experiment parameter

\begin{tabular}{ccc}
\hline control mode & PID & Fuzzy PID \\
\hline Overshoot & $25 \%$ & $22 \%$ \\
\hline Adjust the time(s) & 1.5 & 1.3 \\
\hline Rise time(s) & 0.23 & 0.21 \\
\hline
\end{tabular}

\subsection{The fuzzy PID control of different controlled object}

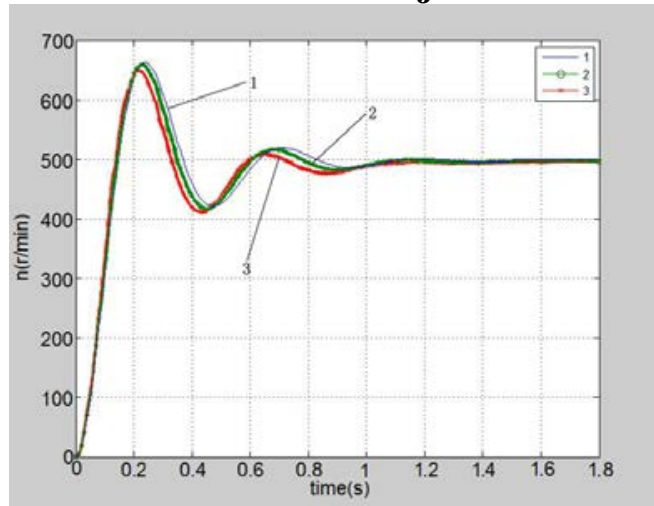

Fig 8. Variable speed curve object

This paper selects three different dc torque motor under the premise of not changing the parameters of the fuzzy controller for speed control experiment, speed response data curve as shown 
in figure 8 , the figure $1,2,3$ curve are corresponding to the dc motor approximate mathematical model: $1 /\left(0.012 s^{2}+1.21 s+1\right), 1 /\left(0.2 s^{2}+3.21 s+3\right), 1 /(4 s+2)$, when motor's structure and parameter changes, the response curve is not change large. Curve 1 's overshoot is about $23 \%$, the time is $1.3 \mathrm{~s}$, rise time is $0.21 \mathrm{~s}$, curve 2 's overshoot is about $26 \%$, the time is $1.2 \mathrm{~s}$, rise time is $0.18 \mathrm{~s}$, curve 3's overshoot is $22 \%$, adjust time of $1.4 \mathrm{~s}$, rise time of $0.23 \mathrm{~s}$. Experimental data shows that when changes occurs, great changes have taken place without the system dynamic characteristics. This is the conventional PID controller cannot be achieved, reflects the huge advantage of fuzzy control algorithm.

\subsection{Experimental summary}

Experiments show that the speed curve of designed fuzzy PID controller's overshoot is 22\%, adjust time is $1.3 \mathrm{~s}$, rise time is $0.21 \mathrm{~s}$, compared with the conventional PID controller parameters are all in 9 13\% improvement, When controlled object changed, the fuzzy controller's response curve of the dynamic characteristic parameters is not big. reflects the huge advantage of fuzzy control in the field of motor speed control.

\section{Conclusion}

In view of the dc torque motor speed control system, this paper first discusses the problems in actual industrial application, based on which put forward the fuzzy PID controller, it combines the advantages of conventional PID control and fuzzy control, realize the real-time online setting of PID parameters, and build the simulation model of the speed control system for experimental verification. The results show that compared with the conventional PID control, the fuzzy control system designed in this paper, the overshoot is about $22 \%$, down by $3 \%$, rise time is $0.21 \mathrm{~s}$, shortened $9.5 \%$, the regulating time is $1.3 \mathrm{~s}$, shortened by $13.3 \%$, dynamic characteristic parameters is superior to the conventional PID controller. And when change the transfer function parameters and structure of the controlled object, the fuzzy controller's response curve is not get a great change. Greatly improve the anti-interference ability and robustness of the system. In this paper, the study and experimental results show that the fuzzy PID control technology being applied in the field of dc torque motor speed control is good, the prospect of the further development is of great significance

\section{Reference}

[1] PANG X L, ZHAO W W, FAN D P.Application Research of DC Moment Motor on Airborne Opto-Electronic Servo System[J].Infrared Technology, 2007, 10.

[2] ZHENG Y W, WANG T Y, LIN L, et al.. Two-axis turn table servo control system based on DSP[J]. LJournal of Mechanical \& Electrical Engineering, 2013, 2:210-213.

[3] ZLIU J F, WU X C, ZHANG Y C. Study on Simulink of BLDCM Control System Based on Matlab/Simulink[J]. JOURNAL OF SHANGHAI UNIVERSITY OF ENGINEERING SCIENCE, 2013, 04: 352-356.

[4] CHEN J Q,XU H Z. Application of PID Controller Based on Iterative Learning in the Control of DC Motor[J]. Waiter \& Motor, 2013, 02: 38-41.

[5] DONG HWA KIM. Intelligent tuning of pid controller for multivariable process using immune network model based on fuzzy set[C]10th IEEE International Fuzzy Systems Conference. Seoul, 2001:94-96.

[6] DONG HAWS KIM. Tuning of a PID controller using an artificial immune network model and local fuzzy set[C]IFSA World Congress and 20th NAFIPS International Conference, Joint 9th. Vancouver, 2001: 2698-2703.

[7] REZA A H, SHAHRAM J, REZA S N. DC motor speed control by self-tuning fuzzy PID algorithm[J]. SPIE, 2014, 23: 1-13. 
[8] HUANG F, WANG Y F, GU J, et al..Design and simulation study of fuzzy parameter self-tuning PID controller[J]. Opt. Precision Eng., 2004, 02: 235-239.

[9] CHEN X J, LI D, BAI Y, et al..Application of type-II fuzzy neural network to adaptive double axis motion control system[J]. Opt. Precision Eng., 2011, 07: 1643-1650.

[10] REN W Z, SHENG L F, CHEN Y Y. Application of Fuzzy controller with self-adjusting function for DC motor speed-regulating system[J]. Opt. Precision Eng., 2003,10: 503-509.

[11] QING Q x, YE H M, YANG X W, et al. Speed Control of Brushless DC Motor Based on Fuzzy RBF Neural Network[J]. Control and instruments in Chemical Industry, 2010, 07: 84- 86.

[12] ZHONG X W, SONG Z C, JIANG Z. Application of Fuzzy PID Control for BLDCM Control System[J]. Control and instruments in Chemical Industry, 2010,08:87-89+93. 